TI 2011-030/2

Tinbergen Institute Discussion Paper

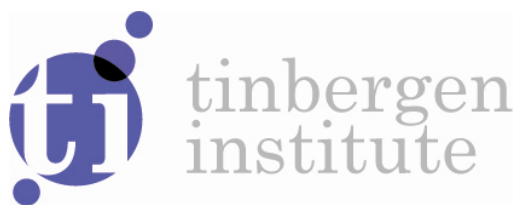

Identifying the Weights in Exchange Market Pressure

Franc Klaassen

Faculty of Business, University of Amsterdam, and Tinbergen Institute. 
Tinbergen Institute is the graduate school and research institute in economics of Erasmus University Rotterdam, the University of Amsterdam and VU University Amsterdam.

More TI discussion papers can be downloaded at http://www.tinbergen.nl

Tinbergen Institute has two locations:

Tinbergen Institute Amsterdam

Gustav Mahlerplein 117

1082 MS Amsterdam

The Netherlands

Tel.: +31(0)205251600

Tinbergen Institute Rotterdam

Burg. Oudlaan 50

3062 PA Rotterdam

The Netherlands

Tel.: +31(0)10 4088900

Fax: +31(0)104089031

Duisenberg school of finance is a collaboration of the Dutch financial sector and universities, with the ambition to support innovative research and offer top quality academic education in core areas of finance.

DSF research papers can be downloaded at: http://www.dsf.nl/

Duisenberg school of finance

Gustav Mahlerplein 117

1082 MS Amsterdam

The Netherlands

Tel.: +31(0)20 5258579 


\title{
Identifying the weights \\ in exchange market pressure
}

\author{
FranC KLAASSEN* \\ University of Amsterdam and Tinbergen Institute
}

January 31, 2011

\begin{abstract}
Exchange market pressure (EMP) measures the pressure on a currency to depreciate. It adds to the actual depreciation a weighted combination of policy instruments used to ward off depreciation, such as interest rates and foreign exchange interventions, where the weights are their effectiveness. The key difficulty in the literature is how to identify these weights. We exploit the persistence of pressure and add instruments based on currency crisis theories to identify the weights, and we propose a simple IV regression to estimate them. An application to the European Monetary System crisis in 1992-1993 shows that a one percentage point higher interest rate wards off a depreciation of about 0.2 percent.
\end{abstract}

Key words: currency crisis models, ERM crisis, exchange rate regime, instrumental variables, monetary policy, persistence.

JEL classification: C26; E42; E58; F31; F33.

*Address: Department of Economics, Roetersstraat 11, 1018 WB Amsterdam, The Netherlands; tel. +31-20-5254191; fax +31-20-5254254; e-mail: f.klaassen@uva.nl.

I would like to thank Henk Jager for stimulating discussions on our EMP project in general, Edo Aalbers for fruitful discussions on this paper, and Maurice Bun, Frank Kleibergen, and seminar participants at Tilburg University and the Tinbergen Institute Amsterdam for very useful and constructive comments. 


\section{Introduction}

Exchange market pressure (EMP) measures the pressure on a currency to depreciate in the foreign exchange (forex) market. For a floating exchange rate, EMP is simply the actual depreciation. For a fixed rate or any intermediate regime, however, authorities use policy instruments such as interest rate and foreign exchange intervention to influence or even completely avoid depreciation. Hence, the actual depreciation no longer reflects the full pressure. The idea of EMP is to add a weighted sum of the policy instruments to the actual depreciation, so that it applies to any exchange rate regime.

But what is the value of the weights? This paper introduces a novel method to estimate them, which boils down to a simple instrumental variable (IV) regression. This provides an alternative to existing approaches.

The currently available weighting methods can be categorized in two groups. First, in their seminal paper, Girton and Roper (1977) use a monetary model of exchange rate determination, which yields a unit weight for the intervention instrument and the interest rate is not used to ward off pressure. Weymark (1995) generalizes that model, leading to weights that depend on unknown parameters, which can be estimated. She provides the insight that a weight is the effectiveness of the instrument (called EMP component) in changing the exchange rate. These papers represent the group of modeldependent weighting methods.

The second group starts from the fact that tying exchange rates to macroeconomic fundamentals is very difficult, and thereby also estimating the true weights from within a structural exchange rate model. This has motivated Eichengreen, Rose, and Wyplosz (1996) to avoid a model and compute the weight of an EMP component as the ratio of two sample standard deviations to achieve that no component dominates in EMP. Pentecost, Van Hooydonk, and Van Poeck (2001) have a related method. These modelindependent methods are convenient to apply, but the estimate reflects not only the effectiveness, but also how much the component is used by the authorities, and one does not know how large this bias is.

The two types of weighting methods can yield very different results. For instance, Stavarek (2010) finds an average correlation coefficient between the model-dependent and model-independent EMPs of only 0.12, and they give even opposite signs in $51 \%$ of the periods. The trade off between the desire to have the effectiveness and to avoid a structural exchange rate model still has not been resolved. This is unfortunate given the popularity of the EMP concept; for instance, see The Economist (2010).

Our goal is to estimate the weights while avoiding a specific structural exchange rate model. Klaassen and Jager (2011) demonstrate that the weights are the effectiveness 
irrespective of the exchange rate generating process. Hence, we actually also intend to estimate the effectiveness, and imposing a full structural exchange rate model does not seem to be a necessity for that. Instead, we build an empirical model for EMP, exploiting its time series features. This almost identifies the weights. We then provide several possibilities to obtain the remaining identifying restriction. So we do impose some structure, of course, but our structure is directly linked to EMP and thereby much less restrictive than a full theoretical model containing the exchange rate as one of many variables. The resulting IV regression provides a framework not just for estimating the weights, but also for testing the underlying specification. Moreover, the approach is flexible and can be adjusted to exploit features of the particular data set at hand.

More specifically, we start by presenting the weights estimation issue as a standard identification problem (Section 2). Our identification strategy consists of two blocks. First, in Section 3 we argue that shocks to EMP are persistent in case of managed exchange rates, but not persistent for floating rates. This is motivated by views expressed by policy makers and by applying the theoretical framework of Engel and West (2005) to EMP. To capture the regime-dependent persistence empirically, we introduce an adjusted first-order autoregressive model for EMP. Substituting the EMP variable by the underlying components and weights yields a simple regression equation that explains the depreciation from the first difference of the other EMP components and the lagged EMP component levels. This reduces the degree of underidentification to one.

The second identification block, discussed in Section 4, starts from the consequence of the first block that the innovation in the model is serially uncorrelated. That facilitates the construction of instrumental variables and we provide several proposals. One can use predetermined external information, such as regarding the timing of decisions to abandon a peg. Another option is to use a direct theoretically motivated (and empirically verified) parameter restriction. Also the literature on currency crisis models delivers several potential instrumental variables. In the end we achieve exact or even overidentification and the weights can be estimated consistently.

The estimated weights yield a time series of estimated EMP. This can be generated for any exchange rate regime, reflecting the encompassing nature of EMP. The latter is one of the reasons why EMP has been used so widely, as countries differ substantially in their exchange rate regime. ${ }^{1}$ For instance, IMF (2007) takes exchange market pressure to study adequate policy responses to capital flows, and the recently developed IMF financial stress index for emerging economies contains EMP as one out of five indicators

\footnotetext{
${ }^{1}$ The IMF (2009a) de facto classification of exchange rate regimes shows that $52 \%$ of 146 currencies have some sort of peg, and $30 \%$ have a managed float with no predetermined path for the exchange rate. See Husain et al. (2005) for further details.
} 
(IMF, 2009b). The idea of pressure is also relevant for country credit ratings, as the Standard and Poor's downgrading of Lithuania on October 27, 2008 has witnessed. Frankel and Wei (2008) and Frankel and Xie (2010) use EMP to estimate de facto exchange rate regimes. Bertoli, Gallo and Ricchiuti (2010) provide some methodological contributions, and Stavarek (2010) relates EMP to de facto regimes for four new EU member states. Finally, The Economist (2010) uses EMP to study capital inflows of emerging markets.

The remainder of this text is organized as follows. After the exposition of the identification problem in Section 2 and the two-block identification procedure in Sections $3-4$, we discuss the estimation procedure in Section 5 . There we also compare our method to the existing weighting methods in more detail. Section 6 presents a case study on the 1992-1993 crisis in the Exchange Rate Mechanism (ERM) of the European Monetary System (EMS). This appears to be a clean and therefore attractive setting to investigate a new methodology. Section 7 concludes.

\section{Identification problem}

The concept of exchange market pressure (EMP), introduced by Girton and Roper (1977), is further formalized in Weymark (1995). We follow her definition in that EMP on a currency is its excess supply on the forex market if policy makers would be "passive", that is, refrain from actions to offset that excess supply, where this (positive or negative) excess supply is expressed in the relative depreciation required to remove it. Consequently, in a floating exchange rate regime EMP coincides with the observed depreciation, whereas in all other regimes EMP is the depreciation-equivalent of excess supply in the counterfactual of a passive policy maker. This is the definition that all authors working on EMP use, either implicitly or explicitly.

As the counterfactual case is not observed, EMP is unobservable. However, if there is pressure, we do observe that policy variables are set to take it away, possibly together with a change in the exchange rate. This section formalizes how this information can be used to measure EMP indirectly, and how that leads to an identification problem, which will be analyzed in subsequent sections.

We consider two countries, domestic and foreign. One of the policy goals of the monetary authorities involved (domestic, foreign, or both) is to manage the exchange rate (though a perfectly free float is a valid special case). This can be the final target, as in case of an exchange rate peg, but it can also be an intermediate objective so as to achieve something else, as in a situation where the authorities try to mitigate depreciation to curb inflation. The crucial point is that the authorities (the central bank 
throughout this article) aim at affecting the exchange rate for some reason. Typical policy instruments used to influence the exchange rate are the interest rate, official interventions on the forex market, and capital controls. For expositional simplicity, we focus on the home country and do as if only the domestic central bank acts to influence the exchange rate.

To measure EMP one combines the actual depreciation with the policy instruments used to influence depreciation. Let $\Delta s_{t}$ denote the actual depreciation, where $s_{t}$ denotes the (logarithm of the) nominal spot exchange rate, defined as the domestic currency price of one unit of foreign currency.

Before the policy instruments enter the EMP measure, they are transformed to measure the extent to which they are used to ward off depreciation. For instance, the interest rate instrument is taken in deviation from the counterfactual rate the central bank would have chosen if it were passive regarding the exchange rate. The transformed instruments (and $\Delta s_{t}$ ) are called EMP components. Klaassen and Jager (2011) explain how to construct the components and show that, under a few assumptions, the form of the components does not depend on the variables that cause pressure, nor on a model of exchange rate determination. Let $x_{t}$ denote the vector of $K-1$ components corresponding to all instruments the central banks uses.

EMP measure $E M P_{t}$ at time $t$ is a weighted combination of $\Delta s_{t}$ and $x_{t}$ assuming time-constant weights. The $\Delta s_{t}$ component enters $E M P_{t}$ with coefficient one, because EMP is expressed in units of depreciation and in a floating exchange rate regime $E M P_{t}$ equals $\Delta s_{t}$. The weights of the components in $x_{t}$ form a vector $w$, where each weight is the effectiveness of the component (loosely speaking, policy instrument) in changing the exchange rate, that is, in offsetting pressure. Hence

$$
E M P_{t}=\Delta s_{t}+w^{\prime} x_{t}
$$

Under the assumptions just referred to, this measure coincides with the actual (unobserved) pressure, so we use $E M P_{t}$ for both the EMP measure and EMP itself.

Operationalization of EMP $P_{t}$ requires specifying $x_{t}$ and $w$. Deriving the components does not require knowing the weights, but finding the weights obviously depends on having the correct components. Therefore, a sequential analysis of first finding the right components and then the weights is warranted. In this paper we assume that the components are observed, and we focus on finding $w$.

A first guess might be to estimate $w$ from $\Delta s_{t}=\alpha-w^{\prime} x_{t}+\varepsilon_{t}$. This involves $K>1$ parameters. One moment condition is the expectation $E\left\{\varepsilon_{t}\right\}=0$. Because any change in $\varepsilon_{t}$ is a change in $E M P_{t}$ and thus at least sometimes means a change in $x_{t}$, the latter is endogenous (actually, $\varepsilon_{t}$ is just the centered $E M P_{t}$ and thus directly related to $x_{t}$ ). 
Variables that are correlated with $x_{t}$ (such as lags $x_{t-1}$, other policy variables, and exchange rate fundamentals) are automatically correlated with $E M P_{t}$ and thus $\varepsilon_{t}$, so that they cannot be used as instrumental variables here. So there are $K$ parameters to be estimated, but $K-1$ are unidentified.

Another try is to add regressors to try to explain $E M P_{t}$. If the added regressors are uncorrelated with the (new) error term $\varepsilon_{t}$, this yields additional moments, but usually also extra parameters. This does not help identification, unless the added regressors make $x_{t}$ uncorrelated with $\varepsilon_{t}$ and/or there are fewer additional parameters than moments. A necessary condition for making $x_{t}$ uncorrelated with $\varepsilon_{t}$ is that $\varepsilon_{t}$ is serially uncorrelated. ${ }^{2}$ A natural approach is to add $E M P_{t-1}$ as regressor (assuming that one lag is enough). This leads to one additional parameter, but the $\Delta s_{t-1}$ and $x_{t-1}$ involved yield $K$ moments. The total number of parameters becomes $K+1$ and we now have $1+K$ predetermined regressors, so that the parameters are identified. However, a pure autoregressive model for $E M P_{t}$ is invalid, as we will demonstrate below. But this deliberation has at least revealed a modeling direction that could succeed in identifying $w$.

Similar to this approach, the main idea of the method developed below is to exploit that $E M P_{t}$ or its components are related to other variables, including their lags. This requires imposing some structure to obtain identification. Of course, the key issue is whether the restrictions involved are reasonable. The identifying conditions are grouped in two blocks. Section 3 exploits the persistence of shocks in $E M P_{t}$ to develop moment conditions, motivated by insights from practice and a theoretical model. Next, Section 4 completes identification by using external information and/or suggestions from currency crisis theories. Section 6 provides some statistical tests of the imposed structure.

\section{Persistence of EMP}

The first indication that shocks to $E M P_{t}$ are persistent in managed exchange rate regimes comes from reports by policy makers. Annual reports by the BIS (1993, p.139, 185-190) on the currency crisis in Europe, BIS (1998, p.38) on East Asia, and the EMP part in the IMF (2009b, p.141) financial stress index on the 2007-2008 crisis all show persistence. Central bank reports confirm the view that pressure can persist for several months.

\footnotetext{
${ }^{2}$ After all, if $\varepsilon_{t}$ remains correlated with its past, say $\varepsilon_{t-1}$, then $\varepsilon_{t}$ correlates with $E M P_{t-1}$ and thus with $x_{t-1}$, which may well correlate with $x_{t}$, so that also $\varepsilon_{t}$ may well correlate with $x_{t}$. Think of market sentiment (in $\varepsilon_{t}$ ) that correlates over time and has caused the central bank to set a high interest rate at $t-1$ and $t$.
} 
However, the actual depreciation $\Delta s_{t}$ is known to exhibit only weak (if any) serial correlation. Hence, for floating exchange rates, where $E M P_{t}=\Delta s_{t}$, pressure is not persistent. Section 3.1 provides a theoretical explanation for the apparent regimedependence of the persistence of shocks, and we then show how to model that empirically.

\subsection{Regime-dependent persistence in the monetary model}

The standard model used to study EMP is the flexible-price monetary model (Girton and Roper, 1977, and Weymark, 1995). It has been used extensively to study floating, fixed, and intermediate regimes, just as EMP encompasses all regimes. We examine how one stochastic process for an exchange rate fundamental can lead to EMP processes in which shocks are more persistent, the higher the degree of exchange rate management. Because later sections only use this result, not the restrictions of the monetary model, we just consider a stylized version of that model.

The model consists of money market equilibrium in the home and foreign countries, uncovered interest parity (UIP), and purchasing power parity (PPP):

$$
\left\{\begin{aligned}
m_{t} & =p_{t}+\gamma y_{t}-\iota \mathrm{i}_{t} \\
m_{t}^{*} & =p_{t}^{*}+\gamma y_{t}^{*}-\iota \mathrm{i}_{t}^{*} \\
\mathrm{i}_{t}-\mathrm{i}_{t}^{*} & =E_{t}\left\{\Delta s_{t+1}\right\} \\
s_{t} & =p_{t}-p_{t}^{*},
\end{aligned}\right.
$$

where $m_{t}=\log \left(M_{t}\right)$ and $M_{t}$ denote (base-)money supply, which has been created by domestic credit of the central bank, $D_{t}$, and the purchase of reserves measured in domestic currency, $R_{t}$, so that $M_{t}=D_{t}+R_{t}$. Furthermore, $p_{t}$ is the log price level, $y_{t}$ is $\log$ real output, $\mathrm{i}_{t}$ is the interest rate level, and the (semi-)elasticities $\gamma$ and $\iota$ are positive. Foreign variables are denoted by asterisks, and $E_{t}$ denotes the expectation operator conditional on time $t$ information.

The central bank only uses reserve changes (not domestic credit) if it wants to control the exchange rate. Assuming that the central bank does not intervene in the counterfactual, where it does not want to influence the exchange rate, the EMP component is $x_{t}=-\Delta R_{t} / M_{t-1}$. The model implies that its weight is $w=1$, which is in line with Girton and Roper (1977). Hence

$$
E M P_{t}=\Delta s_{t}-\Delta R_{t} / M_{t-1} .
$$

The change in reserves $\Delta r_{t}=\Delta R_{t} / M_{t-1}$ depends on the shocks hitting this economy and the degree of exchange rate management. Suppose that the shocks only originate 
from the change in domestic credit creation $\Delta d_{t}=\Delta D_{t} / M_{t-1}$, so domestic and foreign output and foreign money supply and interest rate are constant. The central bank offsets a fraction $\mu \in[0,1]$ of $\Delta d_{t}$ for exchange rate purposes, that is,

$$
\Delta r_{t}=-\mu \Delta d_{t}
$$

Hence, if the exchange rate floats, $\mu=0$. If it is fixed, the regime is credible, and the shocks are small enough to maintain credibility (that is, $\Delta s_{t}=0$ and $E_{t}\left[s_{t+1}\right]=s_{t}$ ) then (2) implies $\Delta m_{t}=0$, so that $\mu=1$, using that (approximately) $\Delta m_{t}=\Delta d_{t}+\Delta r_{t}$. Hence, $\mu$ is the degree of exchange rate management, and values $0<\mu<1$ represent intermediate regimes.

Engel and West (2005) argue that the first difference in the fundamentals can be realistically described by a stationary first-order autoregressive process $\operatorname{AR}(1)$, so that we specify

$$
\Delta d_{t}=\phi \Delta d_{t-1}+\epsilon_{t},
$$

where $E_{t-1}\left\{\epsilon_{t}\right\}=0$ and $0 \leq \phi<1$. The question is what this process implies for the persistence of past shocks in today's $E M P_{t}$ and how that depends on the degree of exchange rate management $\mu$.

To compute $\Delta s_{t}$ in (3), we start from the equilibrium equation from model (2)

$$
\begin{aligned}
s_{t} & =(1-\delta)\left[m_{t}-m_{t}^{*}-\gamma\left(y_{t}-y_{t}^{*}\right)\right]+\delta E_{t}\left\{s_{t+1}\right\} \\
& =(1-\delta) \sum_{h=0}^{\infty} \delta^{h} E_{t}\left\{m_{t+h}-m_{t+h}^{*}-\gamma\left(y_{t+h}-y_{t+h}^{*}\right)\right\},
\end{aligned}
$$

where $\delta=\iota /(1+\iota)$ is the discount factor, and the second equality uses the "nobubbles" condition that $\delta^{h} E_{t}\left\{s_{t+h}\right\}$ goes to zero as the horizon $h \rightarrow \infty$. Hence, as usual, the exchange rate is the discounted sum of current and future fundamentals. Next, take the first difference and use $\Delta m_{t}=(1-\mu) \Delta d_{t}$, as implied by (4), and substitute $\Delta d_{t}$ by the autoregressive process (5). Some algebraic manipulation then gives

$$
\begin{aligned}
\Delta s_{t} & =(1-\mu)\left[\frac{\phi(1-\delta)}{1-\delta \phi} \Delta d_{t-1}+\frac{1}{1-\delta \phi} \epsilon_{t}\right] \\
& =(1-\mu) \frac{1}{1-\phi} \epsilon_{t},
\end{aligned}
$$

where under $\mu=0$ the first line is the same as Engel and West (2005) derive, and the second (approximate) equality relies on their demonstration that $\delta$ is close to unity in the sense that the $\Delta d_{t-1}$-term is virtually zero. As a consequence, $\Delta s_{t}$ is serially uncorrelated, irrespective of the persistence in $\Delta d_{t}$ and of the exchange rate regime. 
The idea is the persistence of today's news $\epsilon_{t}$ in the level of all future $m_{t+h}$ and the large weight of those future values in today's exchange rate $s_{t}$ imply that $\epsilon_{t}$ dominates lagged fundamentals in determining $s_{t}$, so that past shocks do not persist in today's $\Delta s_{t}$.

Finally, substituting (8), (4), and (5) in exchange market pressure (3) yields

$$
E M P_{t}=(1-\mu) E M P_{t}^{\text {float }}+\mu E M P_{t}^{\text {fixed }}
$$

where

$$
\begin{cases}E M P_{t}^{\text {float }} & =\frac{1}{1-\phi} \epsilon_{t} \\ E M P_{t}^{\text {fixed }} & =\phi \Delta d_{t-1}+\epsilon_{t} .\end{cases}
$$

That is, in our model $E M P_{t}$ in any exchange rate regime is a weighted average of $E M P_{t}$ under floating and fixed rates, $E M P_{t}^{\text {float }}$ and $E M P_{t}^{\text {fixed }}$, respectively.

As explained before, past fundamental shocks do not persist in $E M P_{t}^{\text {float }}$. Under fixed exchange rates $(\mu=1)$, however, $\Delta d_{t-1}$ does not drop out. The idea is that shocks $\epsilon_{t}$ are offset by $\Delta r_{t}$, and similarly for the resulting $\Delta d_{t+h}$, so that current and future fundamentals $m_{t+h}$ do not change, and the magnitude of the discount factor plays no role here. Hence, next to $\epsilon_{t}$, past fundamental shocks $\epsilon_{t-h}$ matter for today's $E M P_{t}^{\text {fixed }}$, provided $\phi \neq 0$. Engel and West (2005) argue that realistic values of $\phi$ are 0.3 and 0.5 for their quarterly analysis. That yields 0.669 and 0.794 at the monthly, and 0.987 and 0.992 at the daily frequency. Hence, $E M P_{t}^{\text {fixed }}$ is persistent at the monthly frequency and even more so at the daily frequency.

We conclude from the weighted average in (9) that the persistence of past shocks in current $E M P_{t}$ increases from zero (for $\mu=0$ ) to high values, if the degree of exchange rate management $\mu$ goes up. Still, $E M P_{t}$ remains stationary for any $\mu$, given that the growth in fundamentals is stationary. The persistence also positively depends on the persistence $\phi$ of shocks in fundamentals, which by itself increases with the data frequency. Particularly for fixed rates $(\mu=1)$ observed at the daily frequency $(\phi$ around 0.99 ) shocks are highly persistent. These conclusions from the monetary model support the policy makers' views given earlier.

\subsection{Modeling persistence empirically}

The regime dependence of EMP persistence invalidates the pure autoregressive model for $E M P_{t}$ suggested in Section 2, because in that model the impact of $E M P_{t-1}$ on $E M P_{t}$ is the same irrespective of the regime. The model fails to capture that if all pressure $E M P_{t-1}$ ends up in depreciation $\Delta s_{t-1}$, as in a floating exchange rate regime, 
there will be little (if any) pressure carried over to $E M P_{t}$. To capture this effect empirically, we propose

$$
E M P_{t}=\alpha+\rho\left(E M P_{t-1}-\Delta s_{t-1}\right)+\varepsilon_{t},
$$

where $E_{t-1}\left\{\varepsilon_{t}\right\}=0$. In case of a floating exchange rate, $E M P_{t-1}=\Delta s_{t-1}$, so that $E M P_{t}$ is not persistent. If the exchange rate is fixed, $\Delta s_{t-1}=0$ and the model is a pure AR(1) model, which is capable of explaining the high persistence of $E M P_{t}$, so that we expect a substantial $\rho>0$. In intermediate regimes, the model assumes that pressure escaped via $\Delta s_{t-1}$ is completely irrelevant for expected pressure the next day; $\Delta s_{t-1}$ is a perfect "valve." The higher the degree of exchange rate management, the less pressure is allowed to escape, the larger (in absolute value) $E M P_{t-1}-\Delta s_{t-1}$, so the more persists in $E M P_{t}$. These implications are in line with the conclusions of the previous section.

A priori, it is not clear whether $\Delta s_{t-1}$ indeed completely takes away pressure from the forex market. Moreover, in empirical work one may want to allow for some serial correlation in a floating exchange rate, if only to make inference robust. Hence, in practice one could take $E M P_{t}=\alpha+\rho\left(E M P_{t-1}-\lambda \Delta s_{t-1}\right)+\varepsilon_{t}$, where $\lambda$ can differ from 1. This additional parameter quantifies the lowering of pressure by $\Delta s_{t-1}$, so it is a pressure-valve parameter. In the empirical application we indeed allow for $\lambda \neq 1$. But in the current section we restrict $\lambda=1$ for the ease of exposition, because it will be irrelevant for our key issue of identifying $w$.

\subsection{Moment conditions}

Substitution of EMP measure (1) into (11) gives

$$
\Delta s_{t}=\alpha-w^{\prime} \Delta x_{t}+(\rho-1) w^{\prime} x_{t-1}+\varepsilon_{t} .
$$

The predetermined $x_{t-1}$ yields $K-1$ additional moments, so we now have

$$
\begin{cases}E\left\{\varepsilon_{t}\right\} & =0 \\ E\left\{\varepsilon_{t} x_{t-1}\right\} & =0 .\end{cases}
$$

The price to pay for these additional moments is one extra parameter $\rho$. We thus have $K+1$ parameters and $K$ moments. So persistence model (11) has reduced the degree of underidentification from $K-1$ to 1 and the new error term is no longer serially correlated, which facilitates finding additional instruments. The next section provides ideas to obtain the final identifying restriction. ${ }^{3}$

\footnotetext{
${ }^{3}$ The pure autoregressive model of Section 2, which imposes $\lambda=0$, resulted in identification, because it has $\Delta s_{t-1}$ as a regressor with a restricted coefficient. Unfortunately, subtracting $\Delta s_{t-1}$ to resolve
} 
The reduction in the degree of underidentification comes from specifying the persistence model in terms of the total EMP measure instead of the individual components, so that the impacts of all $K-1$ EMP components in $x_{t-1}$ are restricted to share the same $\rho$ (for $K=2$, the relevant case in the empirical section, this obviously entails no restriction). An exception has been made for $\Delta s_{t-1}$, which has a separate impact $\rho(1-\lambda)=0$ here. After all, $\Delta s_{t-1}$ is crucially different from $x_{t-1}$, as $\Delta s_{t-1}$ relieves pressure from the exchange rate at $t$, while $x_{t-1}$ only temporarily offsets pressure, leading to pressure at $t$. Such a difference does not exist among the components in $x_{t-1}$, so that a common $\rho$ may be reasonable for them.

Nevertheless, it is possible to generalize model (12) by substituting $\rho w^{\prime} x_{t-1}$ by $\left[\rho_{1} w_{1}, \ldots, \rho_{K-1} w_{K-1}\right] x_{t-1}$, so that the $K-2$ restrictions $\rho_{1}=\ldots=\rho_{K-1}=\rho$ are no longer imposed. For instance, if the central bank uses the policy instrument $x_{1}$ at time $t-1$ to fully offset $E M P_{t-1}$, then $E_{t-1}\left\{E M P_{t}\right\}=\alpha+\rho_{1} w_{1} x_{1, t-1}$, whereas using $x_{2}$ yields $E_{t-1}\left\{E M P_{t}\right\}=\alpha+\rho_{2} w_{2} x_{2, t-1}$. Because the full offsetting in both cases implies $w_{1} x_{1, t-1}=w_{2} x_{2, t-1}$, having $\rho_{1}<\rho_{2}$ reflects that, say, speculators withdraw more from the market at $t$ when the first policy tool is used. Component-specific $\rho$ can be allowed if one has additional moment restrictions, possibly obtained along the lines discussed next. For simplicity, however, this paper continues with a common $\rho$.

\section{Completing identification}

Modeling the persistence has lowered the degree of underidentification to one and has made the error term uncorrelated with past information. We now introduce a number of identifying restrictions that can be used to achieve identification or even overidentification.

\subsection{Overnight restrictions}

Although $x_{t}$ is in principle endogenous, there might be cases where one or more of its components are predetermined, or where this gives an acceptable approximation. For instance, decisions to devaluate or suspend a peg and to lower the interest rate and stop official interventions are often taken while the major markets involved are closed, such as during weekends or overnight. This possibility becomes more realistic, the higher

its misspecification removes $\Delta s_{t-1}$ from the mean equation. One could still keep it as instrument and fulfill the order condition of identification, but $\Delta s_{t-1}$ may be quite a weak instrument for $\Delta x_{t}$. So from a practical point of view, resolving misspecification reintroduces underidentification. Allowing for $\lambda \neq 1$ keeps $\Delta s_{t-1}$ as regressor and instrument, but adds another parameter, so that there is again underidentification. Hence, to obtain useful inference, it is advisable to try and find an additional instrument and/or restriction. 
the data frequency. In fact, daily data may well be a necessity for this restriction to be valid. Then it could be reasonable to assume that the decision process underlying a policy instrument $x_{k t}$ is based on information through time $t-1$ only, so that

$$
E\left\{\varepsilon_{t} \Delta x_{k t}\right\}=0
$$

A weaker version results if one does not know the exact value of $\Delta x_{k t}$ at $t-1$, but only that $\Delta x_{k t}$ will change in a specific direction. Think of policy makers who decide overnight to no longer use the interest rate weapon to defend a peg and lower the interest rate depending on market conditions the next day. One way to model such external information is by defining a dummy $a_{t}$, which is one if the monetary authorities decide at time $t-1$ to adjust their policy as of period $t$ so that it correlates with $\Delta x_{k t}$, and assume

$$
E\left\{\varepsilon_{t} a_{t}\right\}=0 .
$$

We will refer to such restrictions as "overnight restrictions." Note that it is sufficient for identification to have such a restriction for just a single policy instrument. Of course, it is important to be convinced that the restriction is reasonable for the case at hand. Ideally, one would like to test it, perhaps by using one of the following proposals for identification.

\subsection{Restricting $\rho=1$}

Section 3 has shown that $\rho$ may be quite large. For instance, at the daily frequency $\rho$ may be close to unity. Hence, $\rho=1$ may be a reasonable restriction. ${ }^{4}$ This simplifies the model into

$$
\Delta s_{t}=\alpha-w^{\prime} \Delta x_{t}+\varepsilon_{t} .
$$

Hence, the change in the components $x_{t}$ matters for estimating $w$, while their level is in the $E M P_{t}$ measure (1).

This observation is also useful when one does not impose $\rho=1$. After all, as long as the true $\rho$ is close to unity, the terms in (12) that involve $w$ can be written as $w^{\prime}\left(x_{t}-\rho x_{t-1}\right)$, which is close to $w^{\prime} \Delta x_{t}$. Hence, for $\rho$ close to or equal to unity, it is

\footnotetext{
${ }^{4}$ Using $\rho=1$ does not imply that $E M P_{t}$ has a unit root. First, one typically uses components based on international interest rate differentials and official interventions in the $x_{t}$-vector. These are stationary, as is $\Delta s_{t}$, so that their combination in $E M P_{t}$ is stationary. This is supported by the monetary model implication in (9)-(10). Still, $\rho=1$ may be a useful approximation in practice. Second, even if $\rho=1$ is literally true, the $E M P_{t}$ process is bounded. After all, if $E M P_{t}$ is very high and persists for some time, being offset by high interest rates and/or severe loss of reserves, then the economic costs of maintaining the peg will ultimately outweigh the benefits and/or reserves will be depleted, and the peg will collapse (see the literature on currency crisis models for a formalization). The resulting depreciation will act as a pressure valve, so that subsequent pressure will be small.
} 
the impact of the change in policy instruments on the depreciation that contains the crucial information on the value of $w$. So to estimate $w$ it is important to have data series where $\Delta x_{t}$ and $\Delta s_{t}$ show substantial time variation, as is typically the case for exchange rate pegs that come under attack and eventually collapse.

After restricting $\rho=1$, the model meets the order condition of identification by using the moments (13). The strength of the level variable $x_{t-1}$ as instrumental variable for the first difference $\Delta x_{t}$ may be large enough for the data series typically used to estimate $w$, because a high $x_{t-1}$ points at pressure that may well break down the peg, after which $x_{t}$ will be decreased. Still, one has to be aware of potential weakinstrument problems for inference, and test for it; see Staiger and Stock (1997). In any case, imposing $\rho=1$ and using $x_{t-1}$ as instrumental variable delivers a simple and quick approach to obtain an idea of $w$. This is remarkable, given that we started with a complete lack of identification of $w$.

\subsection{Instruments from currency crisis theories}

This subsection proposes some potential instrumental variables for the vector $\Delta x_{t}$ in (12) to achieve identification. One expects the largest volatility in $\Delta x_{t}$ around realignments or abandoning of pegs (devaluations, say), and particularly negative $\Delta x_{t}$ as of the date of devaluation. Because we need sufficiently strong correlation with $\Delta x_{t}$, variables that explain devaluation decisions seem promising. Moreover, the instruments must be sufficiently volatile to correlate enough with $\Delta x_{t}$, as the latter can quickly adjust to offset pressure developments.

The literature on currency crises suggests some determinants that fulfill both requirements. The first generation model, pioneered by Krugman (1979), stresses the importance of unsustainable macroeconomic policies that deplete the central bank's foreign reserves. When reserves drop beyond a threshold, a speculative attack occurs. Hence, this strand of the literature suggests that a variable such as $R_{t-1} / M_{t-1}$ correlates (positively) with $\Delta x_{t}$. To capture part of the nonlinearity induced by the threshold, which by itself is unknown, one could use $R_{t-1} / M_{t-1}$ and its square. If forex interventions are included as an EMP component, then the closely related $-\Delta R_{t} / M_{t-1}$ is one element in $x_{t}$. Hence, the suggested instruments may correlate sufficiently with $\Delta x_{t}$. The use of such instruments based on lags is similar to what is often done in the dynamic panel data literature.

The second generation model emphasizes the option of the policy maker to devalue if economic conditions become worse than a threshold (see the escape clause model in Obstfeld, 1997). Examples of such "economic conditions" are interest rates, unemploy- 
ment, and the fiscal position of the government. To quantify this idea, the interest component in EMP is particularly helpful. After all, that component is the actual interest rate minus the counterfactual (or shadow) rate the central bank would have chosen if it had no exchange rate objective, and the latter can account for variables such as the unemployment situation and fiscal position of the government (see Klaassen and Jager, 2011). For example, high unemployment typically means a negative output gap, thus a low Taylor-rule based counterfactual interest rate, and thereby a high interest EMP component for a given actual interest rate. Unemployment can also be included in the counterfactual rate directly. Hence, the interest EMP component provides a useful summary of "economic conditions." The literature thus suggests that a variable such as the lagged interest EMP component, denoted by $i_{t-1}$, correlates with the decision to devalue and thus (negatively) with $\Delta x_{t}$. To capture that the duration of the weak economic conditions plays a role, one could take an average of recent interest component values instead of just the value at $t-1$. The threshold idea is again exploited by adding $i_{t-1}^{2}$ (which is short-hand notation for $i_{t-1} \cdot\left|i_{t-1}\right|$ to capture that highly negative $i_{t-1}$ are expected to come together with positive $\left.\Delta x_{t}\right)$.

The proposals for using $R_{t-1} / M_{t-1}$ and $i_{t-1}$, particularly the average of recent $i$, suggest that it is EMP cumulated through $t-1$ that matters for the devaluation decision. As the temporal aggregation result in Klaassen and Jager (2011) demonstrates, cumulated EMP is exactly how pressure should be measured over multiple periods. This points at a direct link between the currency crisis literature and the one on EMP, an issue considered in Daniëls, Jager and Klaassen (2008), and the potential of cumulative past EMP for predicting currency crises. Moreover, the square of past EMP motivates $R_{t-1} / M_{t-1} \cdot i_{t-1}$ as additional instrument. All this suggests some potentially useful moments: ${ }^{5}$

$$
\begin{cases}E\left\{\varepsilon_{t} R_{t-1} / M_{t-1}\right\} & =0 \\ E\left\{\varepsilon_{t}\left(R_{t-1} / M_{t-1}\right)^{2}\right\} & =0 \\ E\left\{\varepsilon_{t} i_{t-1}\right\} & =0 \\ E\left\{\varepsilon_{t} i_{t-1}^{2}\right\} & =0 \\ E\left\{\varepsilon_{t} R_{t-1} / M_{t-1} i_{t-1}\right\} & =0\end{cases}
$$

\footnotetext{
${ }^{5}$ Note that $i_{t-1}$ cannot be used as instrumental variable if the EMP measure includes the interest component, so that $i_{t-1}$ is a regressor in (12), and if $\rho$ is unrestricted. If $\rho$ is restricted or one takes an average of recent $i$, then $i_{t-1}$ can be included.
} 


\section{Estimation procedure and relation to the literature}

\subsection{IV regression to estimate $w$}

We started the identification procedure with $K$ unidentified parameters $w$ and $\alpha$, and the persistence model (11) has added one parameter $\rho$. The moments (13) together with the suggestions (14), (15), $\rho=1$, and/or (17) can be used to identify all parameters. ${ }^{6}$ Hence, using these conditions instrumental variables (IV) (or generalized method of moments, GMM) estimation of mean equation (12) consistently estimates the weights $w$ in $E M P_{t}$ as well as $\alpha$ and $(\rho-1) w$, from which $\rho$ can be derived.

Section 6 provides an illustration. It pays particular attention to the endogeneity of $\Delta i_{t}$, whether $\rho=1$, the validity of $i_{t-1}$ and $i_{t-1}^{2}$ as instruments, and their strength, and the validity of the structure imposed.

\subsection{EMP literature}

Our method to estimate $w$ differs fundamentally from the two types of approaches in the existing EMP literature. The first approach is based on a structural economic model, with or without estimation. Girton and Roper (1977) use a monetary model similar to (2). The advantage is that the model directly delivers the value of the weight of the intervention component $(w=1)$, so that it requires no estimation. Weymark (1995) generalizes the model, leading to $w \neq 1$, and $w$ depends on model parameters, which she estimates. This allows for variation in $w$ depending on the frequency of the data, as should be (see Klaassen and Jager, 2011).

The main advantage of this methodology is that the weights reflect the effectiveness of the components in offsetting EMP within the model. Moreover, the model dependence of $w$ helps the economic interpretation of the weights. Both are attractive to the extent that the model specification is correct.

The second type of weighting method is based on the sample covariance matrix of the EMP components. Eichengreen et al. (1996) start from the observation that building reasonable empirical models linking macroeconomic fundamentals to exchange rates has proved to be very difficult, particularly over short horizons. Their objective is to prevent that one component dominates the EMP measure in terms of volatility, so they estimate a weight $w_{k}$ by the ratio of the sample standard deviation of $\Delta s_{t}$ to that of $x_{k t}$. This is a volatility-smoothing method. Pentecost et al. (2001) apply principal components analysis to the correlation matrix and take the most volatile

\footnotetext{
${ }^{6}$ But note that $\rho$ is not identified if all components in $x_{t}$ happen to be ineffective. Put differently, if at least one $w_{k} \neq 0$, then $\rho$ is identified.
} 
principle component as the weight $w$. Hence, they do not smooth the volatilities, and they let the data determine the signs of the $w_{k}$, both in contrast to Eichengreen et al. (1996). It is not a priori clear whether volatility smoothing or principal components is the preferable objective.

This methodology avoids the restrictions of a structural model of exchange rate determination, and the weights are easier to compute than in the Weymark (1995) method, but they now reflect not only the effectiveness of the policy instruments as they should - but also how intensively the instruments are used. For instance, if an effective $x_{1 t}$ is used much more than an ineffective $x_{2 t}$, then the higher standard deviation of $x_{1 t}$ leads to a lower weight $w_{1}<w_{2}$ in the Eichengreen et al. (1996) approach, opposite to what it should be (actually, $w_{2}$ should be zero, not positive). Hence, there is a trade off between the two methodologies. The Eichengreen et al. (1996) variant is the most frequently applied one.

Our method does not fit in the two categories, as we do not impose an economic exchange rate model, but still estimate the effectiveness. To achieve this, we have to impose some structure, of course. We model the persistence of $E M P_{t}$ (see Section 3) and propose a set a additional identifying moment conditions (Section 4). This structure is much weaker than a full structural model for the exchange rate, which includes several other variables and equilibrium conditions. We have provided various motivations for our structure, and a number of its elements can be verified empirically.

Other attractive features of our method are the following. The first one concerns the data frequency. Pressure on forex markets is potentially very volatile from day to day and can quickly spread to other markets. Then daily data can reveal interesting developments in the EMP components that are obscured in lower-frequency (say, monthly) data, as Klaassen and Jager (2011) exemplify. In addition, data aggregation may easily result in a loss of information on the interplay between $\Delta s_{t}$ and $x_{t}$ that is crucial for accurate estimation of $w$. It may not even be entirely clear how to interpret weights estimated from aggregated data. For instance, if the interest rate increases during the month to keep the exchange rate fixed but is eventually decreased followed by a depreciation the next day in the same month due to $w>0$, the monthly data show that the high interest rate comes together with depreciation, suggesting $w<0$, simply because the sequential information in the daily data is lost. Weymark's method (in contrast to Eichengreen et al.) requires data on variables such as money supply, goods prices, and output, which are only available at low frequencies such as monthly and quarterly. Hence, her method cannot exploit the daily information. In addition, it requires time series covering many years to end up with enough observations for 
useful inference, which raises the potential problem of structural breaks in the model. In contrast, our method can exploit daily data, not only regarding the information on the EMP components and their interaction, but also for the construction of good instruments.

Still, a monthly analysis can be informative to obtain an overall view of a longer period around a crisis, but Klaassen and Jager (2011) show how to derive monthly weights from daily ones. Finally, for some EMP components, such as official forex interventions, daily data may be unavailable. Nevertheless, also in case of monthly data our approach in Sections 3.2 and 4.3 is valid and provides a framework to formally specify and analyze the weighting problem.

Second, our method estimates the signs of the weights, provides standard errors (that can easily be made robust to conditional heteroskedasticity in daily data), and the IV framework allows for using the full toolbox of specification analysis. This is an advantage over both sample-variance methods. Note that Weymark's method does provide standard errors.

Third, our approach is easy to implement using standard estimation software. It is flexible in the sense that in a specific application the regression model or the set of instruments can be adjusted to exploit particular knowledge about the case at hand. We believe these features make our method a useful alternative to the existing methods.

\section{Empirical illustration}

The goal of the empirical exercise is to show that the methodology introduced above can work. We focus on the methodology and concentrate on daily data.

The case under consideration is the 1992-1993 currency crisis in the exchange rate mechanism (ERM) of the European Monetary System (EMS). In particular, we take the three largest ERM members, France, Italy, and the United Kingdom, all with Germany as the foreign reference country (the same countries as in Klaassen and Jager, 2011). That crisis is particularly attractive for our purpose. After all, there were virtually no capital controls during this crisis and other, complicating issues (for instance insolvency of governments, or a banking crisis) were absent. This provides a relatively clean and stable setting, so that we do not have to discuss case-specific features, which is attractive when introducing a new methodology. The crisis is also well documented. Finally, the fact that multiple comparable countries were struck by the same crisis facilitates robustness checks and may allow for a panel analysis with realistic crosscountry parameter homogeneity restrictions to increase estimation accuracy. 


\subsection{EMP components and data}

There are two EMP components, namely the actual depreciation $\Delta s_{t}$, and an interest rate component denoted by $i_{t}$ to capture the pressure offset by domestic policy, which was used heavily during the ERM crisis. Hence, in the notation above we have $K=2$ and $x_{t}=i_{t}{ }^{7}$

The three exchange rates $s_{t}$ are all direct deutschmark rates fixed by the Bundesbank at the time and used at the Frankfurt Stock Exchange (obtained from the Bundesbank website).

The interest rate component $i_{t}$ is the difference between the actual domestic interest rate and the counterfactual rate the domestic central bank would choose if it had no exchange rate objective. ${ }^{8}$ The actual rate is the overnight interbank rate. Hence, it is a market interest rate, which is supposed to summarize various money market policy instruments used by the central bank. In the counterfactual, central banks typically focus on inflation and output. Hence, the counterfactual rate is based on the Taylor rule (actually, an extended version that partly corrects for omitted monetary policy determinants) and we use real-time forward-looking data to compute the rate. Daily data result from interpolation. Note that a simpler approach, such as taking the nominal interest rate differential between the country under consideration and Germany, or using the current vintage of realized data of inflation and output, could also work, because in crisis periods the volatile actual interest rate dominates the more stable counterfactual one. The data are taken from Klaassen and Jager (2011), to which we refer for more details.

The first graph of each country in Figure 1 provides some insight into the data and $w$, the weight of the interest rate component in EMP, that is, the effectiveness of the interest rate policy instrument to offset pressure. The graphs focus on the two months

\footnotetext{
${ }^{7}$ We thus leave out official forex interventions. One reason is that we have not yet been able to obtain daily intervention data. But even if we had such data, the value added might well be limited. After all, the corresponding weight is the effectiveness of sterilized interventions in avoiding deprecation (unsterlized interventions have an additional impact, but that goes via $i_{t}$, which we account for). More precisely, it is their actual effectiveness, not the perceived one of central bankers. From the literature it is not clear whether this effectiveness differs from zero when the simultaneous determination of the intervention decision and the exchange rate is accounted for; see Galati, Melick, and Micu (2005), among others. Hence, the sterilized intervention weight may be close to 0. Moreover, BIS (1993, p.196197) suggests that the quantity of interventions was moderate compared with forex turnover in the case under consideration, and it is indeed this relative quantity that matters for EMP, as Klaassen and Jager (2011) argue. In total, the weight multiplied by the component may be limited for interventions. Given that the main goal of the current application is to exemplify a new methodology, we leave that component out of EMP.

${ }^{8}$ This differs from the component other authors use, which is typically the first difference of the actual interest rate. As Klaassen and Jager (2011) show, only the first method is consistent with the definition of EMP, and it also improves on the first-difference variant in practice.
} 
around the crisis, that is, July-August 1993 for France, and September-October 1992 for Italy and the UK. The tick mark dates are Mondays.

The interest rate component (grey line) is above zero for all three countries, indicating that their central banks used the interest rate to maintain the peg. The interest rate reductions at the heights of the crises are visible: August 2, 1993 (the first business day after the weekend decision to widen the ERM fluctuation margins), September 14, 1992 (the day after the weekend decision to devalue the Italian lira), September 17, 1992 (the day after Black Wednesday, when Italy and the UK in the evening decided to stop defending their pegs). At all four dates $\Delta s_{t}$ (black line) is strongly positive. This reflects the trade off between $\Delta s_{t}$ and $\Delta i_{t}$ that matters for estimating $w$, as mentioned in Section 4.2. Given that the major decisions were made the day before, as Buiter, Corsetti, and Pesenti (1998) show, and thus also implicitly the decision to lower interest rates, the plots suggest that reducing $i_{t}$ causes the increase in $\Delta s_{t}$. In terms of model (12), this suggests that $w>0$. Dividing $\Delta s_{t}$ by $-\Delta i_{t}$ for the four dates gives 0.48 on average. This provides a first crude insight into the order of magnitude of $w$.

\subsection{Estimation results}

We measure exchange market pressure by $E M P_{t}=\Delta s_{t}+w i_{t}$. To make our results robust to some potential serial correlation in $\Delta s_{t}$, we allow the pressure-lowering effect $\lambda$ of $\Delta s_{t-1}$ to differ from unity (see Section 3.2). The main equation (12) becomes

$$
\Delta s_{t}=\alpha-w \Delta i_{t}+(\rho-1) w i_{t-1}+\rho(1-\lambda) \Delta s_{t-1}+\varepsilon_{t},
$$

where $E_{t-1}\left\{\varepsilon_{t}\right\}=0$. The parameter of interest is $w$, and $\rho$ captures the persistence in EMP.

We first discuss the estimation results, including our baseline result, and pay particular attention to the validity of the instrumental variables used. The outcomes are based on the assumption that all parameters are the same across countries. In the next section we show the robustness of the baseline in this and various other directions. All results are robust to unrestricted heteroskedasticity using the White variance matrix estimator and have been computed using Matlab and Stata. We use a significance level of $5 \%$ throughout the paper.

\subsubsection{OLS}

The first column in Table 1, labeled OLS, reports the results assuming that $\Delta i_{t}$ is predetermined. This represents overnight restriction (14). Because the major peg decisions were made at day $t-1$, this restriction may be reasonable. On the other 
hand, the actual level of $i_{t}$ is determined at day $t$, and central banks may respond to market forces during that day, so that these events affect $i_{t}$.

The estimate of $w, \widehat{w}$, is close to zero. Moreover, that of $\rho$ is well above unity, which is at variance with the suggestions from theory in Section 3.1. But $\rho$ is imprecisely estimated, driven by the small value of $\widehat{w}$ and the non-identification of $\rho$ if $w=0$.

A potential reason for these suspicious results is that the overnight restriction may be violated. To test it, we take the Hausman approach. OLS is consistent under the null hypothesis that $\Delta i_{t}$ is uncorrelated with $\varepsilon_{t}$. To obtain a consistent estimator under the alternative, we rely on Section 4.3. That is, we use the key observation of the second-generation currency crisis model that central banks stop using the interest rate to defend a peg, resulting in a strongly negative $\Delta i_{t}$, when the interest rate exceeds a threshold; that motivates $i_{t-1}^{2}$ as instrumental variable. The Hausman test compares OLS to the IV estimator based on $i_{t-1}^{2}$. Because OLS is not efficient under the null due to heteroskedasticity, we use Creel (2004) to make the test statistic robust. The test has a $p$-value of 0.00 , so clearly rejects exogeneity of $\Delta i_{t}{ }^{9}$

\subsubsection{IV}

Table 1 shows the results of the IV regression using $i_{t-1}^{2}$ as instrument. The estimated effectiveness of $i_{t}$ in offsetting pressure is $\widehat{w}=0.22$ (with standard error 0.06). Hence the interest rate is an effective policy instrument, and an actual rate that is one percentage point higher than the counterfactual rate avoids a depreciation of $0.22 \%$.

The lagged interest rate $i_{t-1}$ has an insignificant impact, which translates into $\widehat{\rho}$ close to unity. This is in line with the theoretical arguments in Section 3.1. Hence, the part of yesterday's pressure that is not relieved via yesterday's depreciation $\Delta s_{t-1}$ fully carries over to today. The $\widehat{\lambda}=0.87$ shows that a depreciation relieves pressure from the exchange rate, and this is almost one-to-one. This is consistent with the low serial correlation typically found for changes in fully floating exchange rates. The estimates of $\rho$ and $\lambda$ reflect the fundamental difference that $s_{t}$ is the market-clearing variable on the forex market (relieves pressure), whereas $i_{t}$ only counteracts equilibration by $\Delta s_{t}$ (maintains pressure). In our view, these results make sense. We consider this model as our baseline.

The IV estimate of $w$ is much higher than the OLS one. To verify that OLS in theory indeed yields a negative bias, we calculate the inconsistency of the OLS estimator of

\footnotetext{
${ }^{9}$ Adding $\Delta i_{t-1}$ to the model gives a $t$-value of 2.82 when estimated with OLS. But also after that extension the Hausman test rejects with a $p$-value of 0.02 (and the estimates do not notably change). To keep the models comparable across columns in Table 1 , we leave out $\Delta i_{t-1}$.
} 
$(\alpha, w,(\rho-1) w)$ under the simplifying restriction $\lambda=1$ (which hardly affects the OLS and IV estimates for the remaining parameters). Some algebraic manipulation yields that the probability limit of the OLS estimator of $w$ is smaller than the true $w$ if $E\left\{\Delta i_{t} \varepsilon_{t}\right\}>0$. This indeed holds, because a high $\varepsilon_{t}$ implies a high $E M P_{t}$ and thus a high $\Delta i_{t}$ (keeping $\Delta s_{t}$ constant and assuming $w>0$ ). Hence, OLS is downward biased. Similarly, the OLS estimator of $(\rho-1) w$ is upward biased if $\operatorname{Cov}\left\{\Delta i_{t}, i_{t-1}\right\}<0$ next to $E\left\{\Delta i_{t} \varepsilon_{t}\right\}>0$. Both bias directions are in line with Table 1 .

We now verify that the first-order nature of EMP persistence model (11) sufficiently captures the serial correlation in $E M P_{t}$ by adding $\widetilde{\rho}\left(E M P_{t-2}-\widetilde{\lambda} \Delta s_{t-2}\right)$ to its right hand side. This boils down to adding $\Delta s_{t-2}$ and $\Delta i_{t-1}$ as regressors in (18). The Wald test $p$-value of 0.53 in Table 1 shows that one lag indeed suffices. The extra lags are also insignificant when added to the first-stage regression for the relevance of $i_{t-1}^{2}$ in explaining $\Delta i_{t}$ next to the other regressors. Adding the lags as instrumental variables also does not help estimate $w$, as still $\widehat{w}=0.23(0.06)$.

The consistency of the IV estimates depends on the validity of the instrument $i_{t-1}^{2}$, and proper standard inference also requires that the instrument is strong enough. Table 1 shows that $i_{t-1}^{2}$ matters for $\Delta i_{t}$ (underidentification is rejected) and that $i_{t-1}^{2}$ seems to be a sufficiently strong instrument (the robust first-stage F-statistic is substantial). The latter explains why the Anderson-Rubin (1949) test of $w=0$, which is robust to potentially weak instruments, also clearly rejects.

Validity of $i_{t-1}^{2}$ as an instrumental variable also requires that it is uncorrelated with $\varepsilon_{t}$. To test this, we restrict $\rho=1$ (as discussed in Section 4.2) and use $i_{t-1}$ as an instrumental variable. The Hansen overidentification test ( $p$-value 0.47 ) does not reject the moment conditions used for estimation. A more direct test of the lack of correlation between $i_{t-1}^{2}$ and $\varepsilon_{t}$ results when including $i_{t-1}^{2}$ as a regressor (using $i_{t-1}$ as the only instrument). The $t$-value is 0.81 , confirming that $i_{t-1}^{2}$ is a valid instrument.

As a final check on the impact of the instrument, we leave out $i_{t-1}^{2}$ and construct an instrument from only external information. That is, we exploit the timing of the four major peg adjustments of the countries involved, as discussed in Section 6.1. All decision were announced the day before. Hence, we define the dummy $a_{t}$ that is one on the four dates and impose overnight restriction (15). Table 1 shows that $\widehat{w}$ increases somewhat (not significantly), just as its standard error. Also the results on $\rho$ and $\lambda$ mentioned above are confirmed.

In summary, $i_{t-1}^{2}$ is a valid and sufficiently strong instrumental variable to deal with the endogeneity of $\Delta i_{t}$. Hence, the baseline results are reliable in this respect. 


\subsubsection{EMP plots}

The even graphs in Figure 1 show the time series of $E M P_{t}$ implied by the baseline estimates. The solid line is the estimate $\Delta s_{t}+\widehat{w} i_{t}$, and the gray band is the $95 \%$ confidence band reflecting the estimation uncertainty in $\widehat{w}$. The graph shows the buildup of pressure in the days before August 2, 1993 for France, and September 14 and 17, 1992 for Italy and September 17, 1992 for the UK. This build-up is not visible in the actual depreciation $\Delta s_{t}$, exemplifying the usefulness of the EMP concept in practice to indicate pressure on the market. The reduction in pressure on the day after these four dates with substantial depreciations reflects the role of $\Delta s_{t}$ as a valve for pressure, confirming the usefulness of allowing for $\lambda>0$ in the mean equation (18). This pressure valve also makes the $E M P_{t}$ lines more mean reverting than the interest rate component alone.

Finally, we go back to the odd graphs. The right axis (for $i_{t}$ ) is the left one (for $\left.\Delta s_{t}\right)$ divided by $\widehat{w}$. Hence, the height of the $i_{t}$ line in units of the left axis is $\widehat{w} i_{t}$ and is directly comparable to the height of the $\Delta s_{t}$ line; both are in depreciation units. This implies that the height of the $i_{t}$ line compared to the $\Delta s_{t}$ line reflects the relevance of $i_{t}$ in $E M P_{t}$ relative to that of $\Delta s_{t}$. The graphs show that France and Italy put more emphasis on using the interest rate to offset pressure than the UK. This is consistent with the common view that for the former two countries exchange rate stability with Germany was considered more important than for the UK.

\subsection{Other specification analyses}

Table 2 reports additional checks of the baseline approach. First, there is no indication of time variation of the parameters. After all, allowing for all four parameters to break between 1992 and 1993 gives an insignificant $p$-value of 0.31 , and it is 0.46 when considering only $w$.

Second, a more direct and theoretically motivated test of the time-constancy of $w$ concerns the potential relevance of $i_{t}$ for the effectiveness $w$ of the interest rate policy instrument. High interest rates may signal that many speculators sell the home currency and can thereby convince more speculators to join, so that the high interest rate acts as a coordinating device and makes the interest rate weapon less effective. We model this by $w_{t}=w_{0}+w_{1} i_{t}$. Substitution in the EMP persistence model (11) yields $-w_{1} \Delta i_{t}^{2}+(\rho-1) w_{1} i_{t-1}^{2}$ as extra term on the right hand side of mean equation (18). This yields two endogenous variables, $\Delta i_{t}$ and $\Delta i_{t}^{2}$. Because of the theoretical suggestion that $\rho=1$ and the earlier empirical support for this as well as the support for the irrelevance of $i_{t-1}^{2}$ as a regressor, we impose $\rho=1$ and use $i_{t-1}$ as an additional 
instrument. The $t$-statistic for $w_{1}$ is -0.67 , so we have no indication that $w$ depends on $i_{t}$.

Third, we question the linear dependence on $\Delta s_{t-1}$ and $i_{t-1}$ by adding $\left(\Delta s_{t-1}\right)^{2}$ and $i_{t-1} \Delta s_{t-1}$ as regressors. The Wald test $p$-value is 0.50 . Adding both variables as instrument changes $\widehat{w}$ into 0.20 (0.06). Again, the baseline results are robust.

The fourth sensitivity check concerns homogeneity in the cross-sectional dimension. Table 2 shows the results when estimating the model for each country separately. The estimates of $w, \alpha, \rho, \lambda$ are quite similar. Most notably, for France and Italy $\widehat{w}$ is close to the baseline value, but for the UK the estimate differs, but not significantly so. The Wald test of full homogeneity has a $p$-value of 0.28 , and the four Wald tests for homogeneity for each parameter separately are all insignificant. Hence, there is also no need for having fixed country effects.

Finally, we extend the sample from 1992-1993 to 1990-1995. The estimated $w$ and $\rho$ decrease a bit (insignificantly so), but again we see no reason to question our baseline results.

\section{Conclusion}

EMP adds a weighted sum of policy variables to the actual depreciation to quantify pressure on a currency in any exchange rate regime. The key difficulty in the EMP literature is how to identify the weights involved. This paper introduces a novel weighting approach, which boils down to an easy-to-implement IV regression. The method combines advantages of existing approaches, as we do not impose a full structural exchange rate model but still estimate the effectiveness of the policy instrument in warding off depreciation. Moreover, our method can exploit the information in daily data, it estimates the signs of the weights, and provides standard errors. These features make it a useful alternative to existing methods.

To identify the weights, we of course have to impose some structure, particularly to account for the simultaneous determination of exchange and interest rates. We have derived from theory that past shocks do not persist in pressure in case of floating exchange rates, but the persistence increases to high levels as the degree of exchange rate management increases, which confirms the views in policy makers' reports. To capture the regime-dependent persistence, we propose an adjusted $\mathrm{AR}(1)$ model. We then use instruments from currency crisis theories (such as the squared lagged interest rate) to achieve full identification, and we also provide some alternative instruments. The weights can then be estimated consistently, and standard IV tests facilitate examining the imposed structure. 
An empirical illustration on the ERM crisis in 1992-1993 yields that the interest rate is an effective policy instrument, where a one percentage point higher rate avoids a depreciation of $0.22 \%$ (standard error 0.06 ). Moreover, the estimates indicate that the part of yesterday's pressure that was not relieved via yesterday's depreciation fully carries over to today's pressure, in line with the theory used. On the other hand, the relieved part of yesterday's pressure is almost completely irrelevant for today's pressure. Hence, depreciation is a pressure valve.

The empirical results also demonstrate that France and Italy put more emphasis on using the interest rate to offset pressure than the UK, confirming the view that for the former two countries exchange rate stability with Germany was considered more important than for the UK. We find no evidence for the view that high interest rates, for instance by signalling massive speculation, attract more speculators and thereby make the interest rate weapon less effective.

EMP has been applied to many phenomena, which opens a wide array of applications for the proposed weighting method. Because the IV regression underlying the method is standard and can be easily adjusted to handle specific features of the data at hand, we hope that the method can be fruitfully applied to many of such cases. Specific applications are left for future research. 


\section{References}

Anderson, T. W. and Rubin, H. (1949), 'Estimation of the parameters of a single equation in a complete system of stochastic equations,' Annals of Mathematical Statistics, 20, 4663.

Bertoli, S., Gallo, G.M. and Ricchiuti, G. (2010), 'Exchange market pressure: some caveats in empirical applications,' Applied Economics, 42, 2435-2448.

BIS (1993), 63rd Annual Report, Basle.

BIS (1998), 68rd Annual Report, Basle.

Buiter, W.H., Corsetti, G.M. and Pesenti, P.A. (1998), 'Interpreting the ERM crisis: country-specific and systemic issues,' Princeton Studies in International Finance, 84 .

Creel, M. (2004), 'Modified Hausman tests for inefficient estimators,' Applied Economics, 36, 23732376.

Daniëls, T.R., Jager, H. and Klaassen, F. (2008), 'Defending against speculative attacks: A hybrid model of exchange market pressure and crises,' Tinbergen Institute Discussion Paper, 08-090/2.

Eichengreen, B., Rose, A.K. and Wyplosz, C. (1996), 'Speculative attacks on pegged exchange rates: an empirical exploration with special reference to the European Monetary System,' in: M.B. Canzoneri, W.J. Ethier, and V. Grilli (eds.), The New Transatlantic Economy, Cambridge: Cambridge University Press, 191-228.

Engel, C. and West, K.D. (2005), 'Exchange rates and fundamentals,' Journal of Political Economy, 113, 485-517.

Frankel, J.A. and Wei, S.-J. (2008), 'Estimation of de facto exchange rate regimes: synthesis of the techniques for inferring flexibility and basket weights,' IMF Staff Papers, 55.3, 384-416.

Frankel, J.A. and Xie, D. (2010), 'Estimation of de facto flexibility parameter and basket weights in evolving exchange rate regimes,' American Economic Review, 100, 568-572.

Galati, G., Melick, W. and Micu, M. (2005), 'Foreign exchange market intervention and expectations: the yen/dollar exchange rate,' Journal of International Money and Finance, 24, 982-1011

Girton, L. and Roper, D. (1977), 'A monetary model of exchange market pressure applied to the postwar Canadian experience,' American Economic Review, 76, 537-548.

Husain, A.M., Mody, A. and Rogoff, K.S. (2005), 'Exchange rate regime durability and performance in developing versus advanced economies,' Journal of Monetary 
Economics, 52, 35-64.

IMF (2007), World Economic Outlook, Washington (D.C.): IMF, October.

IMF (2009a), Annual Report on Exchange Arrangements and Exchange Restrictions, Washington (D.C.): IMF, 19-21. CHECK PAGE NUMBERS

IMF (2009b), World Economic Outlook, Washington (D.C.): IMF, April.

Klaassen, F. and Jager, H. (2011), 'Definition-consistent measurement of exchange market pressure,' Journal of International Money and Finance, 30, 74-95.

Krugman, P. (1979), 'A model of balance-of-payments crises,' Journal of Money, Credit and Banking, 11, 311325.

Obstfeld, M. (1997), 'Destabilizing effects of exchange-rate escape clauses,' Journal of International Economics, 43, 61-77.

Pentecost, E.J., Van Hooydonk, C. and Van Poeck, A. (2001), 'Measuring and estimating exchange market pressure in the EU,' Journal of International Money and Finance, 20, 401-418.

Staiger, D. and Stock, J.H. (1997), 'Instrumental variables regression with weak instruments,' Econometrica, 65, 557-586.

Stavarek, D. (2010), 'Exchange market pressure and de facto exchange rate regime in the euro-candidates,' Romanian Journal of Economic Forecasting, 13, 119-139.

The Economist (2010), 'What you going to do about it?' The Economist, Nov 11, 2010, 84.

Weymark, D.N. (1995), 'Estimating exchange market pressure and the degree of exchange market intervention for Canada,' Journal of International Economics, 39, 273-295. 
Table 1: Estimation results for EMP equation (18)

\begin{tabular}{|c|c|c|c|c|c|c|}
\hline \multicolumn{2}{|c|}{$\begin{array}{l}\text { Instruments for } \Delta i_{t} \text { : } \\
\text { Parameter Regressor }\end{array}$} & \multirow{2}{*}{$\begin{array}{c}\text { OLS } \\
\Delta i_{t} \\
0.03 \\
(0.05)\end{array}$} & \multirow{2}{*}{$\begin{array}{c}\text { IV } \\
i_{t-1}^{2} \\
\text { Baseline } \\
\begin{array}{c}0.22 * \\
(0.06)\end{array}\end{array}$} & \multirow{2}{*}{$\begin{array}{c}\mathrm{IV}_{\rho=1} \\
i_{t-1}^{2} \& i_{t-1} \\
\begin{array}{r}0.24 * \\
(0.06)\end{array}\end{array}$} & \multirow{2}{*}{$\begin{array}{c}\mathrm{IV}_{\rho=1} \\
i_{t-1} \\
0.17 \\
(0.10)\end{array}$} & \multirow{2}{*}{$\begin{array}{c}\text { IV } \\
a_{t} \\
0.38 * \\
(0.11)\end{array}$} \\
\hline$w$ & $-\Delta i_{t}$ & & & & & \\
\hline$w(\rho-1)$ & $i_{t-1}$ & $\begin{array}{c}0.02 \\
(0.01)\end{array}$ & $\begin{array}{c}0.01 \\
(0.01)\end{array}$ & 0 & 0 & $\begin{array}{l}-0.01 \\
(0.01)\end{array}$ \\
\hline$\rho(1-\lambda)$ & $\Delta s_{t-1}$ & $\begin{array}{c}0.13 \\
(0.05)\end{array}$ & $\begin{array}{c}0.13 * \\
(0.06)\end{array}$ & $\begin{array}{r}0.13 * \\
(0.06)\end{array}$ & $\begin{array}{r}0.13 * \\
(0.05)\end{array}$ & $\begin{array}{r}0.13 * \\
(0.06)\end{array}$ \\
\hline$\alpha$ & constant & $\begin{array}{l}-0.05 \\
(0.03)\end{array}$ & $\begin{array}{l}-0.00 \\
(0.03)\end{array}$ & $\begin{array}{c}0.02 \\
(0.01)\end{array}$ & $\begin{array}{c}0.01 \\
(0.02)\end{array}$ & $\begin{array}{l}(0.04) \\
(0.04)\end{array}$ \\
\hline- & $i_{t-1}^{2} / 100$ & 0 & 0 & 0 & $\begin{array}{c}0.10 \\
(0.12)\end{array}$ & 0 \\
\hline$\rho$ & $\begin{array}{l}\text { EMP persistence } \\
\quad \text { if } \Delta s_{t-1}=0\end{array}$ & $\begin{array}{c}1.73 \\
(1.04)\end{array}$ & $\begin{array}{l}1.03 \\
(0.05)\end{array}$ & 1 & 1 & $\begin{array}{c}0.98 \\
(0.04)\end{array}$ \\
\hline$\lambda$ & $\begin{array}{l}\text { EMP lowering } \\
\qquad \text { by } \Delta s_{t-1}>0\end{array}$ & $\begin{array}{c}0.92 \\
(0.05)\end{array}$ & $\begin{array}{c}0.87 * \\
(0.05)\end{array}$ & $\begin{array}{r}0.87 * \\
(0.06)\end{array}$ & $\begin{array}{r}0.87 * \\
(0.05)\end{array}$ & $\begin{array}{r}0.87 * \\
(0.06)\end{array}$ \\
\hline \multirow{5}{*}{\multicolumn{2}{|c|}{$\begin{array}{l}\text { Hausman test of exogeneity of } \Delta i_{t} \\
\text { Add lags } \Delta s_{t-2} \& \Delta i_{t-1}: \text { Wald test } \\
\text { Underidentification: } r k \text { Wald test } \\
\text { Weak identification: first-stage F-stat. } \\
\text { Anderson-Rubin Wald test } w=0\end{array}$}} & {$[0.00]$} & - & - & - & - \\
\hline & & {$[0.02]$} & {$[0.53]$} & {$[0.57]$} & {$[0.47]$} & {$[0.76]$} \\
\hline & & - & {$[0.00]$} & {$[0.00]$} & {$[0.00]$} & {$[0.00]$} \\
\hline & & - & 15.43 & 7.75 & 11.46 & 25.07 \\
\hline & & - & {$[0.00]$} & {$[0.01]$} & {$[0.10]$} & {$[0.00]$} \\
\hline \multirow{2}{*}{\multicolumn{2}{|c|}{$\begin{array}{l}\text { Hansen overidentifying restrictions test } \\
\text { Number of observations }\end{array}$}} & - & - & {$[0.47]$} & - & - \\
\hline & & 1,566 & 1,566 & 1,566 & 1,566 & 1,566 \\
\hline
\end{tabular}

Standard errors in parentheses and $p$-values in square brackets. $*$ denotes significance at the $5 \%$ level, except for OLS, because that relies on an invalid exogeneity condition; for $\rho$ and $\lambda$ the reference value is 1 instead of 0 . Actually, $i_{t-1}^{2}$ means $i_{t-1} \cdot\left|i_{t-1}\right|$, so it has the same sign as $i_{t-1}$. The instrument $a_{t}$ is a dummy that is one on the day $t$ a peg adjustment was implemented based on a decision made before $t$; see Section 6.2 for details. The sample is 1992-1993 for the currencies of France, Italy and the UK vis-à-vis the German mark; daily frequency.

All results are robust to heteroskedasticity using the White (1980) variance matrix estimator. The standard errors for the derived estimates of $\rho$ and $\lambda$ are based on the delta method. For the Hausman test (which compares OLS to IV using $i_{t-1}^{2}$ ) we use Creel (2004) to obtain this robustness, while the underidentification test is due to Kleibergen and Paap (2006). The (robust) F-test statistic for the relevance of $i_{t-1}^{2}$ in explaining $\Delta i_{t}$ next to the other regressors can be assessed by using the rule of thumb of Staiger and Stock (1997) that the F-statistic should be at least 10 for weak identification not to be a problem, as suggested by Baum, Schaffer and Stillman (2007) and others. For the AndersonRubin (1949) test we replace $\Delta i_{t}$ in (18) by a linear combination of the instruments, and apply the Wald test of a zero impact of those instruments, so that the test is robust to potential weakness of the instruments. 
Table 2: Sensitivity analysis and diagnostics of baseline estimates

\begin{tabular}{|c|c|c|c|c|c|c|}
\hline \multirow[b]{2}{*}{ Parameter } & \multirow[b]{2}{*}{ Meaning } & \multicolumn{5}{|c|}{ IV estimation of (18) using $i_{t-1}^{2}$ as instrument } \\
\hline & & Baseline & Fra & Ita & UK & $1990-95$ \\
\hline$w$ & $-\Delta i_{t}$ impact & $\begin{array}{r}0.22 * \\
(0.06)\end{array}$ & $\begin{array}{r}0.17 * \\
(0.06)\end{array}$ & $\begin{array}{r}0.22 * \\
(0.07)\end{array}$ & $\begin{array}{c}0.47 \\
(0.41)\end{array}$ & $\begin{array}{r}0.15 * \\
(0.06)\end{array}$ \\
\hline$\alpha$ & constant & $\begin{array}{l}-0.00 \\
(0.03)\end{array}$ & $\begin{array}{c}0.01 \\
(0.04)\end{array}$ & $\begin{array}{c}0.01 \\
(0.04)\end{array}$ & $\begin{array}{l}-0.02 \\
(0.06)\end{array}$ & $\begin{array}{r}0.02 * \\
(0.01)\end{array}$ \\
\hline$\rho$ & $\begin{array}{r}\text { EMP persistence } \\
\text { if } \Delta s_{t-1}=0\end{array}$ & $\begin{array}{l}1.03 \\
(0.05)\end{array}$ & $\begin{array}{c}0.99 \\
(0.07)\end{array}$ & $\begin{array}{c}1.04 \\
(0.08)\end{array}$ & $\begin{array}{c}1.04 \\
(0.10)\end{array}$ & $\begin{array}{c}0.95 \\
(0.03)\end{array}$ \\
\hline$\lambda$ & $\begin{array}{l}\text { EMP lowering } \\
\qquad \text { by } \Delta s_{t-1}>0\end{array}$ & $\begin{array}{r}0.87 * \\
(0.05)\end{array}$ & $\begin{array}{c}1.00 \\
(0.09)\end{array}$ & $\begin{array}{r}0.83 * \\
(0.06)\end{array}$ & $\begin{array}{c}0.94 \\
(0.10)\end{array}$ & $\begin{array}{r}0.92 * \\
(0.03)\end{array}$ \\
\hline \multicolumn{2}{|c|}{ Time-constant param.: Wald } & {$[0.31]$} & - & - & - & - \\
\hline \multirow{3}{*}{\multicolumn{2}{|c|}{$\begin{array}{l}w \text { independent of } i_{t}: t \text {-test } \\
\text { Add }\left(\Delta s_{t-1}\right)^{2} \& i_{t-1} \Delta s_{t-1}: \text { Wald } \\
\text { Underident.: } r k \text { Wald test }\end{array}$}} & {$[0.51]$} & - & - & - & - \\
\hline & & {$[0.50]$} & - & - & - & - \\
\hline & & {$[0.00]$} & {$[0.00]$} & {$[0.00]$} & {$[0.00]$} & {$[0.00]$} \\
\hline \multicolumn{2}{|c|}{ Weak ident.: first-stage F-stat. } & 15.43 & 27.44 & 14.40 & 13.98 & 22.06 \\
\hline \multicolumn{2}{|c|}{ Anderson-Rubin Wald test $w=0$} & {$[0.00]$} & {$[0.03]$} & {$[0.01]$} & {$[0.33]$} & {$[0.01]$} \\
\hline \multicolumn{2}{|c|}{ Number of observations } & 1,566 & 522 & 522 & 522 & 4,689 \\
\hline
\end{tabular}

See the notes to Table 1 for details. The time-constant parameters test allows the four parameters to change from 1992 to 1993 under the alternative. To test whether $i_{t}$ matters for $w$, we impose $\rho=1$ and use $i_{t-1}$ as an additional instrument. 
FRANCE

EMP components $\Delta s_{t}$ (dark, left axis) and $i_{t}$ (light, right axis)

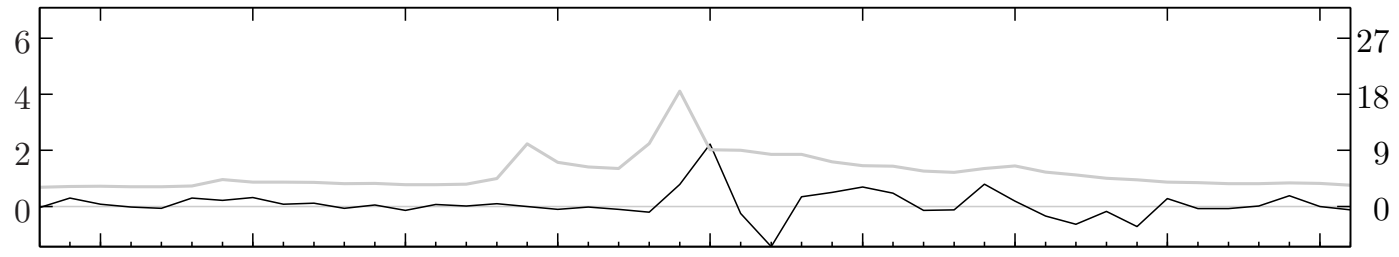

EMP measures based on IV-weights (solid, with 95\% band) and ERW-weights (dashed)

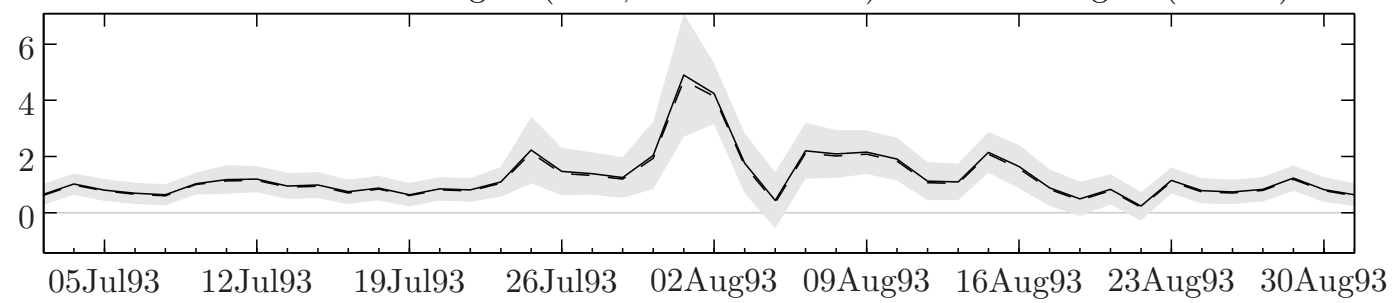

ITALY

EMP components $\Delta s_{t}$ (dark, left axis) and $i_{t}$ (light, right axis)

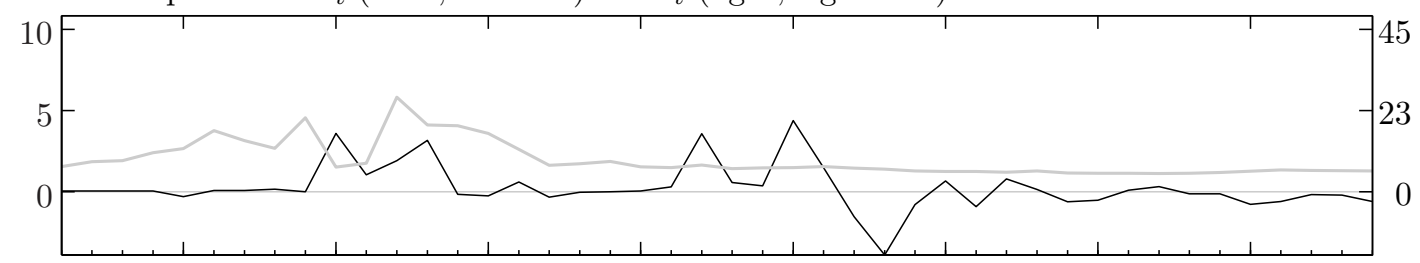

EMP measures based on IV-weights (solid, with 95\% band) and ERW-weights (dashed)

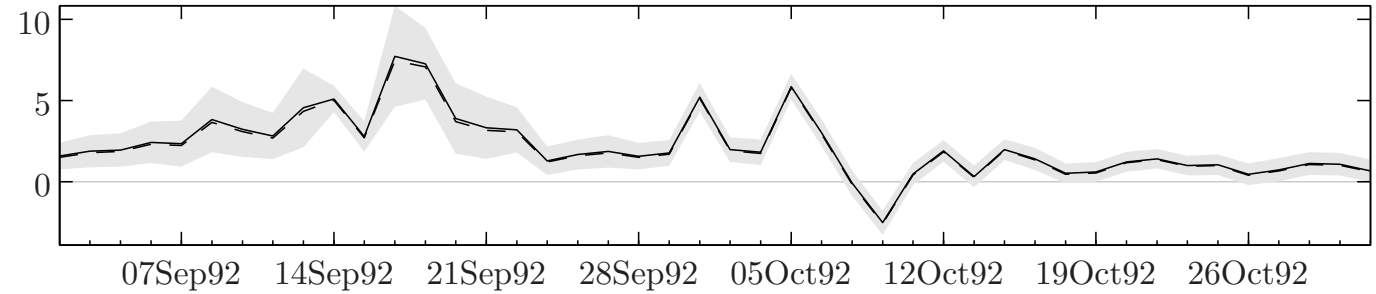

UNITED KINGDOM

EMP components $\Delta s_{t}$ (dark, left axis) and $i_{t}$ (light, right axis)

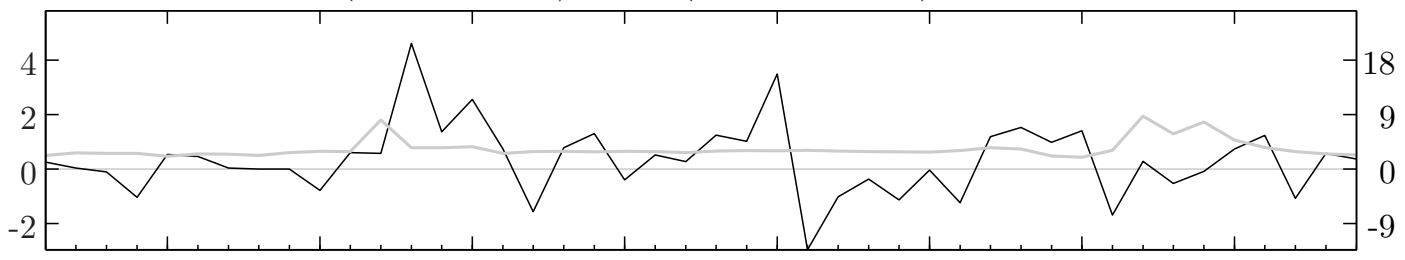

EMP measures based on IV-weights (solid, with 95\% band) and ERW-weights (dashed)

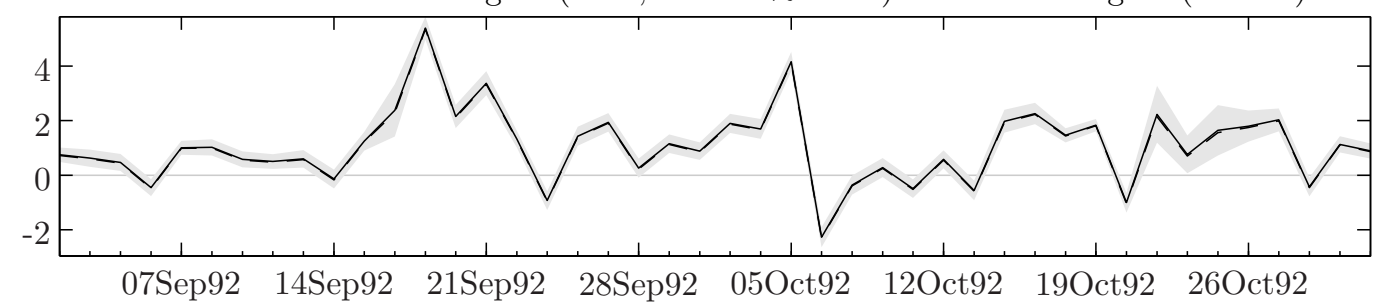

Figure 1: Daily EMP components and total EMP measures. 